\title{
Altered Reward Reactivity as a Behavioural Endophenotype in Eating Disorders: A Pilot
}

\section{Investigation in Twins}

Authors names and affiliation:

Natalie Kanakam ${ }^{\text {PhD a }}$, Isabel Krug ${ }^{\text {PhD b }}$, David Collier ${ }^{\text {PhD c }}$ and Janet Treasure ${ }^{\text {PhD FRCP FRCPsych a }}$,

a King' s College London, Institute of Psychiatry, Eating Disorders Research Group, 103 Denmark Hill, London, United Kingdom, SE5 8AZ.

${ }^{\mathrm{b}}$ School of Psychological Sciences, University of Melbourne, Victoria, Australia

${ }^{c}$ Social, Genetic and Developmental Psychiatry Centre, De Crespigny Park, Denmark Hill, London, United Kingdom, SE5 8AF

First author email address: natalie.kanakam@gmail.com

First author phone number: (+44) 07730435582

This research was in part funded by a Medical Research Council Scholarship awarded to Natalie Kanakam

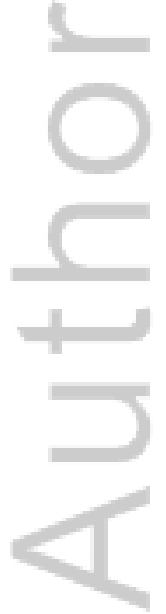

This is the author manuscript accepted for publication and has undergone full peer review but has not been through the copyediting, typesetting, pagination and proofreading process, which may lead to differences between this version and the Version of Record. Please cite this article as doi: $10.1002 /$ erv.2512 


\section{$\underline{\text { Abstract }}$}

Altered reward reactivity is a potential risk endophenotype for eating disorders (ED). The aim of this study was to examine reward reactivity in female twins with EDs and compare it to a twin control group. A sample of 112 twins [ $n=51$ met lifetime DSM-IV ED criteria (anorexia nervosa $n=26$; bulimic disorders $n=24), n=19$ unaffected cotwins and $n=42$ control twins] were administered measures assessing reward reactivity, including the Game of Dice task (GDT), the Behavioural Inhibition/Activation Scales (BIS/BAS) and the Appetitive Motivation Scale (AMS). Within pair correlations for monozygotic (MZ) and dizygotic twins were calculated and generalised estimating equations compared probands, with non-eating disorder cotwins and controls. The BAS and the AMS were reduced in eating disorders and negatively associated with restrictive symptoms. In addition monozygotic twins pairs demonstrated significant within pair similarity for the BAS and AMS.

Conversely, there was less evidence to support the BIS or risky decision making as measured by the GDT as an endophenotype in EDs.

Keywords: Endophenotypes; Eating disorders; Neuropsychology; Reward reactivity; Genetic 


\section{Introduction}

Across the eating disorder (ED) spectrum, there is an altered balance between reward and inhibition (Wierenga et al., 2013). Altered reward sensitivity occurs in patients with opiate dependence (Brand, Roth-Bauer, Driessen, \& Markowitsch, 2008), pathological gambling (Brand, Kalbe, et al., 2005) and those with attention deficit hyperactivity disorder (Drechsler, Rizzo and Steinhausen, 2009), BED (Svaldi et al., 2010) and BN (Brand et al., 2007). However in patients with anorexia nervosa (AN), altered reward sensitivity presents with symptoms of anhedonia, self-denial of food and other pleasures (Kaye et al., 2013). Whereas those with bulimia nervosa (BN) display poor impulse control and engage in novelty seeking behaviours (Kaye et al., 2013). Underlying these behaviours are alterations in the corticostriatal limbic and dorsal cognitive neural circuitry which are systems involved in reward from food and self-control (Wierenga et al., 2013).

It has been difficult to determine whether alterations in reward reactivity are premorbid features, staterelated, or scars from the illness that persist after recovery (Frank, 2013). A further complication is that ED behaviours contribute to alterations in the brain's reward system, which may promote the illness and contribute to relapse (Frank, 2013). Genetically informative samples can help to inform whether altered reward reactivity is a premorbid feature by exploring whether the feature fulfils endophenotype criteria as defined by Gottesman and Gould (2003). Previous research using this paradigm of endophenotype criteria (Gottesman \& Gould, 2003) has led to evidence that cognitive and emotional styles may be endophenotypes of EDs. For example difficulties in set-shifting appear to persist after recovery from AN indicating that it may have been premorbid to the illness (Holliday, Tchanturia, Landau, Collier and Treasure, 2005). Furthermore difficulties in set-shifting and weak central coherence are familial traits that are present in unaffected sisters of those with EDs and research in twins indicates that these traits are heritable (Holliday et al., 2005; Kanakam, Raoult, Collier and Treasure, 2012; Roberts, Tchanturia and Treasure, 2010; Roberts, Tchanturia and Treasure, 2013; Tenconi et al., 2010). Lastly, research in twins has shown that difficulties in emotion 
recognition and attentional biases to social stimuli are also present in unaffected twin siblings and heritable in people with EDs (Kanakam et al., 2013). At this time there have been limited studies examining whether reward reactivity is an endophenotype of EDs. As such this study aims to investigate the endophenotype status of altered reward reactivity measured by self-report measures and a neuropsychological task. The following sections will outline the current evidence base.

\section{Self-Report Measures of Reward Reactivity in Eating Disorders}

Studies using the Behavioural Inhibition/Activation (BIS/BAS) scales (Carver and White, 1994), have shown that people with EDs have higher levels of behavioural inhibition and lower levels of behavioural activation in comparison to controls (Harrison, Treasure and Smillie, 2011; Harrison, O'Brien, Lopez and Treasure, 2010). Similarly the scores on the Appetitive Motivation Scale (AMS), are reduced in people with EDs (Harrison et al., 2011; Jackson and Smillie, 2005). There are also differences in reward reactivity across the ED spectrum, with AN being the least reactive to reward and associated with higher levels of behavioural inhibition and bulimic types being the most reactive to reward and having higher levels of behavioural activation (Harrison et al., 2011). This pattern appears to remain after recovery (Harrison et al., 2011).

The genetic basis or familial risk of altered reward reactivity measured by the BIS/BAS Scales (Carver and White, 1994) or the AMS (Jackson and Smillie, 2005) has not been assessed in people with EDs. Nevertheless, there is evidence from clinical ED samples that reward reactivity is a shared familial risk factor, which is present in unaffected sisters of those with AN (Karwautz, Rabe-Hesketh, Collier and Treasure, 2002; Wade et al., 2008). However, unlike twin studies, which compares monozygotic twins with dizygotic twins to determine the effects of heritability alone, familial studies cannot determine whether the similarities are due to non-shared environment, shared environment or genes.

Neuropsychological Measures of Reward Reactivity in People with Eating Disorders 
Gambling tasks may also be of clinical significance, since better decision making is associated with great improvements in nutritional status in patients with AN following a cognitive behavioural treatment programme (Cavedini et al., 2006). A meta-analysis of 23 studies using the lowa Gambling Task (IGT) indicated that people with EDs make disadvantageous choices with moderate to large effect sizes (Hedges' $g$ : -0.72 in AN, -0.62 in BN, and -1.26 in BED) (Guillaume et al., 2015). The review showed that participants with anorexia-purging (AN-P) type had lower net scores on the IGT compared with AN (Guillaume et al., 2015). Individuals with BN demonstrated more risky decision making on the Game of Dice task (GDT) (Brand et al., 2005) in comparison to people with AN,AN-BP and healthy controls (Brand, Frankie-Sievert, Jacoby, Markowitsch and Tuschen-Caffier, 2007). Other bulimic disorders (BD), such as BED have demonstrated similar patterns of more risky decision making on the task (Svaldi, Brand and Tuschen-Caffier, 2010). Overall there appears to be evidence that altered decision making is associated with eating disorders.

There is limited research with regards to the endophenotype status of decision making deficits measure by simulated gambling tasks. The previously mentioned meta-analysis of the IGT indicates that patients recovered from AN, have similar scores to healthy controls, suggesting it may not be a premorbid feature (Guillaume et al., 2015). Genetically informative samples can also be useful in determining whether altered reward reactivity is a premorbid feature in the absence of longitudinal studies. One study that used genetically informative samples has shown that poor performance on the IGT is present in unaffected relatives of those with AN and influenced by genetic effects (heritability indices: 0.40), indicating that it is in part a premorbid feature (Galimberti et al., 2012).

\section{The Current Study}

The aim of the current study was to examine whether altered reward reactivity measured by the selfreport measures: BIS/BAS (Carver and White, 1994), the AMS (Jackson and Smillie, 2005) and the neuropsychological task: GDT (Brand et al., 2005) fulfils the criteria for being an endophenotype. A 
twin sample provided a natural experiment to parse out the effects of genetic and environmental influences on the behaviour (Plomin, De Fries, McClearn and McGuffin, 2001).

Three criteria used to define endophenotypes as outlined by Gottesman and Gould [(2003) p.639] were investigated for reward sensitivity -1 ) its' 'heritability', by comparing monozygotic and dizygotic twins with the expectation that performance within monozygotic twin pairs will be more similar (i.e. significantly correlated) since they share $100 \%$ of genes, in comparison to dizygotic twin pairs who share only $50 \%$ of genes, on average (Plomin et al., 2001); 2) the 'co-segregation with the illness in families' by comparing their unaffected cotwins with controls twins and 3) the 'association with the illness in the population': a) by comparing the whole group of twins with EDs with control twins and b) by comparing probands with $\mathrm{AN}$ and $\mathrm{BD}$ with control twins.

\section{Method}

\section{Ascertainment and Recruitment}

A total of $82(73.2 \%)$ female twins with and without EDs from the St. Thomas UK twin registry (www.twinsuk.ac.uk) (comprised of 12,000 twins representative of the general population) responded to a newsletter, advertising the study. Additional twins were recruited from a previous study conducted by Holland, Sicotte and Treasure in (1998) $(n=14,12.5 \%)$. The remainder $(n=16,14.3 \%)$ were recruited through advertisements posted on the departmental website for the Eating Disorder Research Unit at, King's College London. The twins were ascertained on the basis of clinical status and zygosity.

\section{$\underline{\text { Participants }}$}

In total, 112 twins (56 female twin pairs) participated, aged 16 to 60 . Self-defined ethnicity indicated that the majority (91\%) were White British. Zygosity was determined by a DNA test for $73.2 \%$ of the 
twins. The remaining cases (26.8\%) were administered the 'peas in a pod' questionnaire (96 -98\% accurate) to determine zygosity as advised by the UK Twin Registry (Peeters, Van Gestel, Vlietinck, Derom and Derom, 1998). The National Adult Reading Test (Table 1) indicated that no patient or control participant had clinical evidence of minor intellectual disability (Nelson and Wilson, 1991).

The ED sample included 16 twin pairs where both twins had a lifetime history of an ED (14, monozygotic and 2 dizygotic pairs) and 19 twin pairs where only one twin had a lifetime history of an ED (11 monozygotic and 8 dizygotic pairs). Therefore in total, there were 51 twins who had a diagnosis of an ED and 19 unaffected cotwins. The probandwise concordance rate for a lifetime ED diagnosis was $72 \%$ in monozygotic twins and $33 \%$ in dizygotic twins.

From the group of twins who reported having an ED in their lifetime $(N=51), 62.8 \%(n=32)$ reported that they were now recovered from their ED. Recovery was defined as having no behavioural or psychological symptoms associated with EDs for two or more years (Uher et al., 2003). In total 6 twins were currently underweight, defined as having a body mass index (BMI) below 18.5.

Twins with EDs were separated by diagnosis into two broad groups 1) 'bulimic disorder' ( $n=26)$ [comprised of BN, eating disorder not otherwise specified-bulimia nervosa (EDNOS-BN) and binge eating disorder (BED) as proposed by Van den Eynde and colleagues (2011) and 2) AN ( $n=24)$ (including anorexia nervosa-restrictive (AN-R), AN-BP and eating disorder not otherwise specifiedanorexia nervosa (EDNOS-AN)] (DSM-IV, 1994). One monozygotic twin with eating disorder not otherwise specified-inappropriate compensatory behaviours (EDNOS-inappropriate compensatory behaviours) was excluded from this grouping. In total only $39.2 \%(n=20)$ had received treatment.

Twenty two patients in total experienced diagnostic crossover: 12 had a diagnosis of BN preceded by AN, 10 patients had a diagnosis of AN-BP or AN-P preceded by AN-R and 1 patient had a diagnosis 
of $\mathrm{BN}$ preceded by inappropriate compensatory behaviours. In total 27 patients did not experience diagnostic crossover and had a stable diagnosis across the life course; 10 patients had a diagnosis of BN, 14 patients had a diagnosis of AN-R, 2 patients had a diagnosis of BED and 1 patient had a diagnosis of inappropriate compensatory behaviours.

The healthy control group included 17 monozygotic and four dizygotic twin pairs.

\section{Exclusion and Inclusion Criteria}

Twins were excluded if they had a visual impairment without a corrective aid, a neurological condition, a head injury, current epilepsy, or an intelligence quotient (IQ) below 70 (measured by the National Adult Reading Test, (Nelson and Wilson, 1991).

Clinical twins were included if they had a primary lifetime ED diagnosis (DSM-IV-TR criteria, 2002) or a history of EDNOS-inappropriate compensatory behaviours and their cotwin (unaffected or also with an ED) was able to participate. Due to the difficulties in recruiting twins with EDs, the present study included twins with ED in many different phases of the illness, such as those who were currently recovered.

Control twin pairs were included if both had a healthy BMI between $19-25 \mathrm{~kg} / \mathrm{m}^{2}$ and had no personal or family history of an ED or other psychiatric diagnosis. They were excluded if they scored above the cut-off on one or more self-report measure that screened for the presence of disordered eating behaviour [Eating Disorder Diagnostic Scale (Stice, Telch and Rizvi, 2000)] obsessive compulsive behaviour (Obsessive Compulsive Inventory-Revised, (Foa et al., 2002) as well as depression (20>), anxiety (14>) or stress (25>) (Depression Anxiety and Stress Scale, (Lovibond and Lovibond, 1998)].

\section{Clinical Assessment}


All twins with EDs and non-ED cotwins were interviewed using the EATATE (Anderluh, Tchanturia, Rabe-Hesketh, \& Treasure, 2003) to obtain a lifetime history of ED symptoms and childhood obsessive compulsive personality traits. It was administered by a trained doctoral researcher and diagnosis was confirmed by a clinician. The semi-structured interview is comprised of a European adaptation of the Longitudinal Interval Follow-up Evaluation (Keller et al., 1987) and the Eating Disorders Examination Questionnaire Version (Fairburn \& Cooper, 1993). It has been used previously in research of AN (Anderluh, Tchanturia, Rabe-Hesketh and Treasure, 2009) and demonstrates good inter-rater reliability in terms of diagnoses (kappa 0.82-1.0) and illness history variables (0.80-0.99).

Patients were diagnosed on the basis of symptoms displayed over the life course. Longitudinal changes in diagnosis often occur. For example a substantial number of patients with AN later develop $\mathrm{BN}$ and therefore it may be questioned whether it is appropriate to diagnose the patient as AN for research purposes (Micali et al. 2007). Therefore a hierarchical model of diagnosis was adopted whereby patients with BN irrespective of whether they had a previous history of $\mathrm{AN}$, were classified as having a lifetime diagnosis of BN. This method was adopted by the Price Foundation Collaborative Group's genetic studies and in other familial risk studies in eating disorders (Kaye et al. 2000; Micali et al. 2007). This is based on the premise that patients with BN are phenotypically different to patients with a lifetime diagnosis of AN (Micali et al. 2007).

\section{Self-Report Measures Assessment of Reward Reactivity}

\section{The Behavioral Inhibition and Activation Scales (Carver and White, 1994)}

The BIS/BAS (Carver and White, 1994) is a 20-item questionnaire designed to assess two general motivation systems of behaviours and affect. The BIS assesses the inhibition of behaviour due to fear of anxiety or punishment. The BAS assesses the responsiveness to reward cues. Participants are required to respond to each statement using a 4-point likert scale ranging from 1 ('very true for me') to 
4 ('very false for me'). In our sample Cronbach's alpha was 0.75 for the BIS, 0.79 for the Behavioural Activation Reward Responsiveness Scale, 0.82 for the Behavioural Activation Drive Scale and 0.81 for the Behavioural Activation Fun-Seeking Scale.

\section{The Appetitive Motivation Scale (Jackson and Smillie, 2005)}

The AMS (Jackson and Smillie, 2005) is an 11-item measure of core reward reactivity, which reflects features similar to those measured by the BAS. It assesses the value felt from obtaining a reward as well as the motivation to approach ideas and physical stimuli. Participants are required to indicate to what extent they agree with each statement using a 4-point likert scale ranging from 1 (strongly disagree) to 4 (strongly agree). In Jackson and Smillie's (2005) sample the Cronbachs alpha was 0.83 for the full scale indicating adequate internal consistency. In this sample the Cronbachs alpha was 0.77 .

Experimental Measures Assessment of Reward Reactivity

\section{Game of Dice Task (Brand et al., 2005)}

The GDT (Brand et al., 2005) is a computerised task that measures decision making under conditions of reward and punishment. By rolling the dice, participants can gamble virtual money. The outcome variable is the number of risky choices with a higher score indicating a more risky strategy. The task is described as having good convergent validity in that it has previously shown risky decision making in patients with opiate dependence (Brand, Roth-Bauer, Driessen, \& Markowitsch, 2008), pathological gambling (Brand, et al., 2005), attention deficit hyperactivity disorder (Drechsler, Rizzo and Steinhausen, 2009), BED (Svaldi et al., 2010) and BN (Brand et al., 2007).

\section{$\underline{\text { General Assessment }}$}


The National Adult Reading Test (Nelson and Wilson, 1991) provides an indication of premorbid IQ. A greater number of incorrect pronunciations indicate a lower premorbid IQ. The outcome score correlates positively with overall performance on the British version of the Wechsler Adult Intelligence Scale (Crawford and Parker, 1998).

\section{Procedure}

Information and consent forms were sent prior to the appointment. Self-report questionnaires and diagnostic interviews were completed on the day of testing. This study was approved by the South London and Maudsley NHS Trust Research Ethics Committee.

\section{Statistical Methods}

Intraclass correlation coefficients were calculated for monozygotic and dizygotic twins with EDs. These correlations analyse how strongly twin 1 resembles twin 2. Intraclass correlation coefficients could not be conducted for the control twin sample since the dizygotic control twin sample size was too small $(n=8)$.

For the familial analysis, differences between 'ED twins' (monozygotic and dizygotic probands), 'nonED cotwins' (monozygotic and dizygotic non-ED cotwins) and control twins (monozygotic and dizygotic control twins) were analysed using the Generalised Estimating Equation (GEE) model for non-independent data (Liang and Zeger, 1986) (see Table 2). This accounts for the correlative nature of twin pairs (i.e. controls for zygosity). A logarithm transformation was used for the GDT risky choices outcome variable due to this not being normally distributed. Age was included as a covariate throughout since age differed between groups although not at statistical significance. Depression and anxiety are highly comorbid with EDs, therefore it can be difficult to tease these symptoms apart. For these reasons similar research that has investigated reward sensitivity in eating disorders have chosen not to control for depression and anxiety (Svaldi, Brand and Tuschen-Caffier, 2009; Brand et 
al. 2007).Therefore to ensure that the findings of the present study could be interpreted within a wider evidence base it was also decided not to control for depression and anxiety. A second analysis was conducted using the GEE model to compare diagnostic differences between AN and BD twins and their unaffected twin siblings with controls (Table 3).

To allow for accurate reporting of behaviour in this exploratory study of twins, outliers were not excluded from the analysis. This method for treating outliers replicates previous familial research into neuropsychological traits in people with EDs (Goddard and Treasure, 2013; Kanakam et al., 2013, 2012).

Performance was assessed separately for AN and bulimic disorder groups (as defined in the participant section). Non-ED cotwins were separated on the basis of their probands diagnosis into the non-AN cotwins and non-bulimic disorder cotwin groups. Due to the limited sample size for EDNOSinappropriate compensatory behaviours $(n=1)$, this twin and her non-ED cotwin were excluded from the analysis (see Table 3). Differences between the AN-R and AN-BP groups could not be explored statistically since these groups were too small.

Cohen's d effect sizes were calculated for each comparison with an effect size calculator, using descriptive statistics that were based on the age covariate. Differences are defined as negligible $(\geq$ 0.0 and $<0.15$ ), small $(\geq 0.15$ and $<0.40)$, moderate $(\geq 0.40$ and $<0.75)$, large $(\geq 0.75$ and $<1.10)$, very large $(\geq 1.10$ and $<1.45)$ and huge $(\geq 1.45)$.

Spearman's Rho correlation coefficients assessed associations between the reward reactivity measures and the duration of clinical features in twins with EDs. In line with Rothman's (1990) 
argument, a correction for multiple testing was not required for group comparisons since the outcome variables were related. All analyses were carried out using PASW statistics version 22.0.

\section{$\underline{\text { Sample Size and Power }}$}

The sample size in the present study was limited by the number of twins with EDs it was possible to recruit. Due to the exploratory nature of this study a post hoc power analysis was conducted using GPower software. This indicated that the present sample would have $47 \%$ and $14 \%$ power for detecting group differences between twins with $\mathrm{BD}$ or $\mathrm{AN}$ and controls at the 0.05 level for the GDT respectively (Harrison, Macare, Cardi, Kanakam and Treasure, 2012). In addition, the present sample would have $99 \%$ power for the BIS, 68\% power for BAS (Harrison et al., 2011) and 94\% power for the AMS (Jackson and Smillie, 2005) in detecting group differences between twins with EDs and controls at the 0.05 level.

\section{$\underline{\text { Results }}$}

In Table 1 the ED twins, non-ED cotwins and controls were separated on the basis of zygosity and clinical status. There were no significant differences between the groups for age (Wald Chi Square: 7.3, $d f=4, p=0.12$ ) or IQ (Wald Chi Square: $3.3, d f=4, p=0.51$ ). However the groups were significantly different for BMI (Wald Chi Square: 11.2, $\mathrm{df}=4, \mathrm{p}=0.02$ ), with unaffected twin sisters and control twins presenting with a higher BMI than twins diagnosed with a lifetime history of an ED.

\section{INSERT TABLE 1 HERE}

The following analysis explores three endophenotype criteria as outlined by Gottesman and Gould (2003). The first is that the trait should be associated with the illness. Therefore a correlational analysis was conducted to explore whether the behavioural measures were predictive of clinical features. Furthermore levels of reward reactivity were compared between eating disorder twins and 
controls twins to explore whether the trait was associated with the illness. The second criteria was that the trait should co-segregate with the illness in families and therefore be present in the unaffected cotwins of those with eating disorders. Lastly the third endophenotype criteria of 'heritability' (Gottesman and Gould, 2003) were explored in twins with EDs and their unaffected cotwins. It is expected that monozygotic twin pairs would have higher within pair similarity since they share $100 \%$ of genes, in comparison to dizygotic twin pairs who share only $50 \%$ of genes, on average (Plomin et al., 2001).

Tables 2 presents a comparison of measures assessing reward reactivity in ED twins, non-ED cotwins and controls and Table 3 presents this comparison sub-divided by diagnosis.

\author{
INSERT TABLE 2 AND 3 HERE
}

Summary of the Behavioural Inhibition Scale (Carver and White, 1994) as associated with eating disorders, a familial and heritable trait: Higher scores on the BIS were associated with a lower 'current BMl' ( $r=-0.30, p=0.04)$ and a lower 'lowest BMl' attained $(r=-0.30, p=0.04)$. The behavioural inhibition score was not significantly associated with any clinical features or age.

Overall twins with EDs had a significantly higher behavioural inhibition score in comparison to controls with a medium effect size $\left(d=0.5, p=0.01^{\star *}\right)($ Table 2$)$. Non-BD cotwins had a significantly higher behavioural inhibition score in comparison to controls with a large effect size $(d=1.2, p=0.0)$ (Table 3$)$.

The monozygotic within-pair correlation $[r=0.26(\mathrm{Cl}:-0.15-0.60) \mathrm{p}=0.10]$ for the BIS and the dizygotic within-pair correlation $[r=0.52(\mathrm{Cl}:-0.16-0.85) \mathrm{p}=0.06]$ did not reach statistical significance, indicating limited genetic effects. 
Summary of the Behavioural Activation Scale (Carver and White, 1994) as associated with eating disorders, a familial and heritable trait: A higher level of behavioural activation was associated with a lower duration of illness, [in years $(r=-0.42, p=0.00)$ ] dieting [in months $(r=-0.35$, $p=0.02)$ ], fasting [in months $(r=-0.44, p=0.00)]$ and laxative abuse [in months $(r=-0.29, p=0.05)$ ] across the life course. In addition higher levels of behavioural activation was associated with higher levels of appetitive motivation $(r=0.75, p=0.00)$. Higher scores on the BAS were associated with a lower age $(r=-0.39, p=0.01)$.

Twins with EDs had a significantly lower behavioural activation score in comparison to controls with a medium effect size $\left(d=-0.5, p=0.01^{\star \star}\right)($ Table 2$)$. Twins with AN $\left(d=-0.6, p=0.03^{\star}\right)$ and BD $(d=-0.6$, $p=0.05^{\star}$ ) both had lower BAS scores in comparison to controls (Table 3). Non-BDs cotwins ( $d=-0.9$, $\left.\mathrm{p}=0.05^{\star}\right)$ had a significantly lower behavioural activation score in comparison to controls with a large effect size (Table 3).

Monozygotic twins had significant within-pair similarity $\left[r=0.64(\mathrm{Cl}: 032-0.83) p=0.00^{\star *}\right]$ for the BAS, suggesting that this trait might be influenced by genetic effects. However this was not the case for dizygotic twins [r=-0.39 (Cl: $-0.82-0.33) p=0.86]$.

Summary of the Appetite Motivation Scale (Jackson and Smillie, 2005) as associated with eating disorders, a familial and heritable trait: Similar to reward reactivity measured by the BAS, higher scores on the AMS were associated with a lower duration of illness [in years $(r=-0.53, p=0.00)$ ] dieting [in months $(r=-0.38, p=0.01)$ ], fasting [in months $(r=-0.42, p=0.00)$ ], laxative abuse [in months $(r=-0.39$, $\mathrm{p}=0.01)]$ and number of years of having a BMI below 17.5. Higher scores on the AMS were also associated with a lower age $(r=-0.42, p=0.00)$. 
There were no significant differences between groups indicating limited a familial contribution to this trait (Table 3).

For reward reactivity measured by the AMS, monozygotic twins had significant within-pair similarity, therefore suggesting a genetic basis to this trait $\left[r=0.66(\mathrm{Cl}: 0.36-0.84) p=0.00^{\star \star}\right]$. The dizygotic twin within-pair correlation did not demonstrate significant within pair similarity $[\mathrm{r}=-0.74(\mathrm{Cl}:-0.93--0.20)$ $\mathrm{p}=0.99]$.

Summary of the Game of Dice Task performance (Brand et al., 2005) as associated with eating disorders, a familial and heritable trait: Risky decision making on the GDT was not significantly associated with any clinical features or age.

Overall twins with EDs $(d=0.0, p=0.52)$ and their non-ED cotwins $(d=0.0, p=0.81)$ did not differ from controls for the number of risky choices made (Table 2).

For risky decision making measured by the GDT, neither the monozygotic twin pairs $[r=0.20,(\mathrm{Cl}:-0.21$ $-0.54), p=0.17]$ nor the dizygotic twin pairs $[r=-0.07(\mathrm{Cl}:-0.65-0.56) p=0.58]$ had significant withinpair similarity, indicating limited genetic effects.

\section{Discussion}

This study explored whether altered reward reactivity may be considered as an endophenotype of EDs by examining aspects of this trait in twins with EDs compared to control twins. Diagnostic differences were also explored between twins with BD that typically present with impulse control behaviours and twins with AN that are more likely to present with anhedonic symptoms (Kaye et al., 2013). Higher levels of behavioural inhibition and lower levels of reward reactivity (measured by the BAS) were found in twins with EDs (medium effect sizes). There was also evidence for a genetic 
basis to reward reactivity (measured by the BAS and AMS), but not for behavioural inhibition. There was little evidence to support GDT performance as a familial or genetic trait. Due to the low statistical power specifically for sub-group comparisons on the GDT, any conclusions for this measure should be regarded as tentative and further replication is needed.

\section{Self-Report Measures of Reward Reactivity in Eating Disorders}

Altered reward reactivity (measured by the BAS) fulfilled the endophenotype criteria, since it was elevated in twins with eating disorders and unaffected AN twins. The BAS also appeared to demonstrate within-pair similarity in MZ twins. However behavioural inhibition was not found to be heritable, as there was no evidence for significant within pair similarity in monozygotic twins with EDs $[r=0.26(\mathrm{Cl}:-0.15-0.60) p=0.10]$. Comparatively, in a study of healthy controls, genetic factors accounted for approximately one third of the variance in the behavioural inhibition (34\%) and behavioural activation traits (35\%) (Takahashi et al., 2007). It could be that the genetic/environmental causes of behavioural inhibition differ between people with EDs and controls. Furthermore behavioural inhibition may be a more complex trait than reward reactivity, since it includes two features of inhibition; 'top down' behavioural inhibition due to cognitive control or 'bottom up' suppression of behaviour due to fear of punishment (Nigg, 2000).

Higher behavioural activation and appetitive motivation scores were predictive of a lower duration of restrictive ED behaviours (i.e. fasting and dieting). This suggests that people who are more responsive to reward cues are less likely to engage in anhedonic behaviours such as dieting and use of compensatory behaviours such as fasting for prolonged periods of time. This supports research which indicates that individuals with restrictive EDs have a superior ability to delay reward and that this difference between bulimic and restrictive disorders may be rooted in abnormalities in the dopamine system (Bailer et al., 2013; Kaye et al., 2013). 


\section{Neuropsychological Measurement of Reward Reactivity}

Overall this study found minimal effects on the GDT ( $d=0$ to $d=0.3$ ) compared to previous research, which found much larger effect sizes ( $d=-0.5$ to $d=-0.9)$ for risky decision making in people with $B N$ and BED (Brand et al., 2007; Svaldi et al., 2010). This could be accounted for by the present sample, which was a heterogeneous diagnostic case mix of people at various stages of the illness and recovery.

The present study's findings may also reflect the GDT's reduced sensitivity to detect differences in smaller clinical samples compared to the BIS/BAS self-report measure (Brand et al., 2005; Carver and White, 1994). This was indicated by the relatively low levels of statistical power attained by the GDT (BN: $47 \%$ and AN: 14\%) compared to the BIS/BAS measures (BIS: $94 \%$, BAS: $68 \%$ ) and AMS (94\%) (Brand et al., 2005; Carver and White, 1994; Jackson and Smillie, 2004).

This study found little evidence for familial or genetic effects on the GDT performance. This differs from a study of people with AN and their unaffected sisters, which found familial factors to account for variation in performance on the IGT (Galimberti et al., 2012). The IGT and the GDT may differ in some of the cognitive and emotional sub-functions required for executing the task. In the GDT, participants are given explicit instructions about the monetary gains or losses associated with each choice. However in the IGT, this is implicit. Therefore differences might be accounted for by the different cognitive processes involved. The aforementioned diagnostic mix of recovered and EDNOS participants in the ED group may also in part account for difficulties in determining genetic influences. In addition there were more monozygotic twins $(15.4 \%)$ currently underweight $(\mathrm{BMI}<18.5)$ in comparison to the dizygotic (0\%) group. Given the influence of ED behaviours on the brain's neurochemistry and endocrinological effects that exacerbate symptoms, it is inevitable that the largely recovered state of the present sample influenced the findings (Frank, 2013; Herpetz-Dahlman, Holtkamp and Konrad, 2012). 


\section{Limitations}

There are limitations associated with the sample that was used. The limited sample size means that this study was exploratory and any conclusions are drawn tentatively. It was difficult to recruit control twins and twins where at least one participant had a clinically significant eating disorder. This meant there was insufficient statistical power most notably for the group comparisons using the GDT. However it is noted that previous research which investigated diagnostic differences between AN and BD types on the GDT also had comparably small sample sizes. For example Brand and colleagues (2007) had only 15 patients in their clinical group of BN and 15 in their control group.

Compared to previous research investigating the features of altered reward reactivity in eating disorders (Svaldi, Brand and Tuschen-Caffier, 2009; Harrison et al, unpublished data; Brand et al. 2007) the present study's sample was largely recovered which restricts our comparisons to previous research. In addition more MZ twins were currently ill (56.1\% recovered) compared to DZ twins (83.3\% recovered) which may have affected group comparisons. Nevertheless the number of probands that were currently underweight $(\mathrm{BMI}<18.5)$ were only marginally greater in the $\mathrm{MZ}$ group (14.6\%) in comparison to the DZ (0\%) group. Furthermore it was decided to combine patients with BN and BED (47.2\%) into an over-arching BD group since these patients share the same symptomatology and due to the limited sample size of patients with BED $(n=2)$.

Third, the clinical sample was older in age than samples used in previous research into reward reactivity. This may have affected the findings especially since reward reactivity as measured by the BAS $(r=-0.39, p=0.01)$ and AMS $(r=-0.42, p=0.00)$ was found to reduce as age increased in the present study. 
Fourth in this study we chose not to exclude those with depression and/or anxiety in our clinical sample, due to this being a common comorbidity in eating disorders. However, it is well acknowledged that depression and anxiety can amplify deficits in neurocognitive function and this may have influenced our findings (McClintock et al. 2010; Owens et al. 2014)."

$\underline{\text { Implications }}$

The present study indicates that reduced reward reactivity (measured by the BAS and AMS) is a prognostic indicator of restrictive behaviours and that this feature has aspects that have a familial and/or heritable basis. As such it may be suggested that reward reactivity is an endophenotype that has specific significance for the risk and prognosis of EDs. Previous research has already shown the value of using other neuropsychological assessments in determining prognosis. For example poor cognitive flexibility measured by the Brixton task and Wisconsin Card Sorting Test was found to be associated with a longer duration of illness and more severe eating disorder rituals (Roberts et al 2010).

\section{$\underline{\text { Conclusions }}$}

The present study aimed to examine whether aspects of reward reactivity could be considered as an ED endophenotype. The findings suggest that higher reward sensitivity may protect against prolonged periods of restrictive ED behaviours. Furthermore reward reactivity measured by the BAS was reduced in ED twins and their unaffected twins. In addition monozygotic twin pairs demonstrated significant within pair similarity. Conversely, there was less evidence to support a strong familial or genetic basis to measures, which require a balance between 'top down' control (cognitive inhibition) and 'bottom up' processes (impulses to emotion and reward), such as the BIS or the GDT. Due to the evolving nature of inhibitory processes and reward reactivity with time and as a consequence of disrupted eating patterns, future studies could adopt longitudinal designs as well as larger samples to explore and confirm the present study's findings. 


\section{Acknowledgements}

This research was in part funded by the Medical Research Council Scholarship awarded to Natalie Kanakam. The authors acknowledge training/support from the Institute of Psychiatry, King's College London. We would like to thank the Department of Twin Research \& Genetic Epidemiology Kings College London for their help with recruiting the twins. Lastly, we are most grateful to all the twins and thank them for their participation.

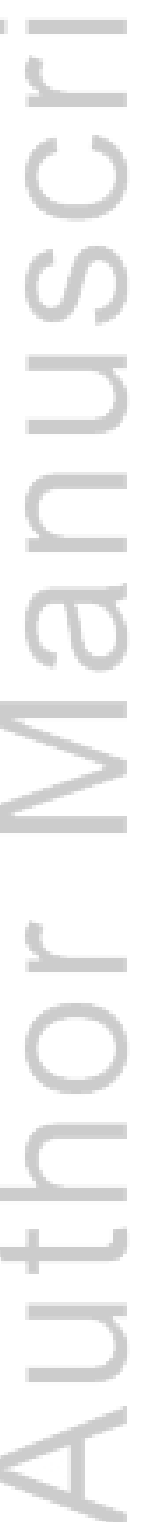

This article is protected by copyright. All rights reserved. 


\section{$\underline{\text { References }}$}

Anderluh, M, B., Tchanturia, K., Rabe-Hesketh, S. and Treasure, J. (2003). Childhood obsessivecompulsive personality traits in adult women with eating disorders: defining a broader eating disorder phenotype. American Journal of Psychiatry, 160, 242-247.

Anderluh, M, B., Tchanturia, K., Rabe-Hesketh, S., Collier, D., and Treasure, J. (2009). Lifetime course of eating disorders: design and validity testing of a new strategy to define the eating disorders phenotype. Psychological Medicine, 39(1), 105-114.

American Psychiatric Association. (2000). Diagnostic and Statistical Manual of Mental Disorders IVRevised (DSM) (Vol. IV--TR). American Psychiatric Press Inc: Washington DC.

Bailer, U., Frank, G., Price, J., Meltzer, C., Becker, C. and Mathis, C., (2013). Interaction between serotonin transporter and dopamine D2/D3 receptor radioligand measures is associated with harm avoidant symptoms in anorexia and bulimia nervosa. Psychiatry Res. 211, 160-8. doi:

10.1016/j.pscychresns.2012.06.010

Brand, M., Frankie-Sievert, C., Jacoby, G.E., Markowitsch, H.J. and Tuschen-Caffier, B., (2007). Neuropsychological correlates of decision making in patients with bulimia nervosa. Neuropsychology 21, 74-750: doi: 10.1037/0894-4105.21.6.742

Brand, M., Fujiwara, E., Borsutzky, S., Kalbe, E., Kessler, J. and Markowitsch, H.J., (2005). Decisionmaking deficits of korsakoff patients in a new gambling task with explicit rules: associations with executive functions. Neuropsychology 19, 267-277. 
Brand, M., Roth-Bauer, M., Driessen, M. and Markowitsch, H. J. (2008). Executive functions and risky decision-making in patients with opiate dependence. Drug and Alcohol Dependence. 97, 64-72.

Bulik, C.M., Sullivan, P.F., Wade, T.D., Kendler, K.S. (2000). Twin studies of eating disorders: A review. International Journal of Eating Disorders 27, 2 - 20

Carver, S.C., White, L.T., (1994). Behavioural inhibition, behavioural activation, and affective responses to impending reward and punishment: the BIS/BAS scales. J. Pers. Soc. Psychol. 67, 319333.

Cavedini, P., Zorzi, C., Bassi, T., Gorini, A., Baraldi, C. and Ubbiali, A., (2006). Decision-making functioning as a predictor of treatment outcome in anorexia nervosa. Psychiatry Res. 145, 179-187.

Claes, L., Mitchell, J.E. and Vandereycken, W., (2012). Out of control?: Inhibition processes in eating disorders from a personality and cognitive perspective. Int. J. Eat. Disord. 45, 407-414. doi:doi:

10.1002/eat.20966

Claes, L., Nederkoorn, C., Vandereycken, W., Guerrieri, R., Vertommen, H., (2006). Impulsiveness and lack of inhibitory control in eating disorders. Eat. Behav. 7, 196-203. doi:doi:

10.1016/j.eatbeh.2006.05.001

Crawford, J.R. and Parker, D.M., (1998). Prediction of WAIS IQ with the National Adult Reading Test: Cross-validation and extension. Br. J. Clin. Psychol. 28, 267-273. 
Drechsler, R., Rizzo, P. and Steinhausen, H.-C., (2009). Decision Making with Uncertain Reinforcement in Children with Attention Deficit/Hyperactivity Disorder (ADHD). Child Neuropsychol. 16, 145-161. doi:doi: 10.1080/09297040903190774

Ehrlich, S., Geisler, D., Ritschel, F., King, J.A., Seidel, M., Boehm, I., Breier, M., Clas, S., Weiss, J., Marxen, M., Smolka, M.N., Roessner, V. and Kroemer, N.B., (2015). Elevated cognitive control over reward processing in recovered female patients with anorexia nervosa. J Psychiatry Neurosci 40, 307-315. doi:doi: 10.1503/jpn.140249

Fairburn, C. \& Cooper, Z. (1993). The eating disorder examination. In: Fairburn, C. G. and Wilson, C. G. eds. Binge eating: nature, assessment and treatment. Guilford Press: New York. 317-331.

Foa, E.B., Huppert, J.D., Susanne, L., Robert, L., Rafael, K., Greg, H. and Salkovskis, P.M., (2002). The Obsessive-Compulsive Inventory: Development and Validation of a Short Version. Psychol. Assess. 14, 485-496.

Frank, G., (2013). Altered Brain Reward Circuits in Eating Disorders: Chicken or Egg? Curr. Psychiatry Rep. 15. doi:doi:10.1007/s11920-013-0396-x.

Galimberti, E., Fadda, E., Cavallini, M.C., Martoni, R.M., Erzegovesi, S. and Bellodi, L., (2012). Executive functioning in anorexia nervosa patients and their unaffected relatives. Psychiatry Research. Advance online publication. Psychiatry Res. doi:doi: 10.1016/j.psychres.2012.10.001.

Goddard, E. and Treasure, J., (2013). Anxiety and Social-Emotional Processing in Eating Disorders: Examination of Family Trios. Cogn. Ther. Res. 37, 890-904. 
Gottesman, I.I. and Gould, T.D., (2003). The endophenotype concept in psychiatry: etymology and strategic intentions. Am. J. Psychiatry 160, 636-645.

Guillaume, S., Gorwood, P., Jollant, F., Van den Eynde, F., Courtet, P. and Richard-Devantoy, S., (2015). Impaired decision-making in symptomatic anorexia and bulimia nervosa patients: a metaanalysis. Psychol. Med. 45, 3377-3391.

Harrison, A., Macare, C., Cardi, V., Kanakam, N. and Treasure, J., (2012). Experimental measurement of reward sensitivity and impulsivity in eating disorders. (in preparation)

Harrison, A., O'Brien, N., Lopez, C. and Treasure, J., (2010). Sensitivity to reward and punishment in eating disorders. Psychiatry Res. 177, 1-11. doi:doi: 10.1016/j.psychres.2009.06.010.

Harrison, A., Treasure, J. and Smillie, L.D., (2011). Approach and avoidance motivation in eating disorders. Psychiatry Res. 188, 396-401. doi:doi: 10.1016/j.psychres.2011.04.022

Herpetz-Dahlmann, B., Holtkamp, K. and Konrad, K., (2012). Eating disorders: anorexia and bulimia nervosa, in: Handbook of Clinical Neurology. pp. 447-459.

Holland, A.J., Sicotte, N. and Treasure, J., (1998). Anorexia nervosa: Evidence for a genetic basis. J. Psychosom. Res. 32, 561-571. doi: 10.1016/0022-3999(88)90004-9

Holliday, J., Tchanturia, K., Landau, S., Collier, D. and Treasure, J. (2005) Is impaired set-shifting an endophenotype of anorexia nervosa? American Journal of Psychiatry, 162, 2269-2275. doi:10.1176/appi.ajp.162.12.2269 
Jackson, C.J. and Smillie, L.D., (2005). The appetitive motivation scale and other BAS measures in the prediction of Approach and Active Avoidance. Personal. Individ. Differ. 38, 981-998. doi:doi: 10.1016/j.paid.2004.09.013

Kanakam, N., Krug, I., Raoult, C., Collier, D. and Treasure, J., (2013). Social and Emotional Processing as a Behavioural Endophenotype in Eating Disorders: A Pilot Investigation in Twins. Eur. Eat. Disord. Rev. 21, 294-307.

Kanakam, N., Raoult, C., Collier, D. and Treasure, J., (2012). Set shifting and central coherence as neurocognitive endophenotypes in eating disorders: A preliminary investigation in twins. World J. Biol. Psychiatry. doi:10.3109/15622975.2012.665478

Karwautz, A., Rabe-Hesketh, S., Collier, D. and Treasure, J., (2002). Pre-morbid psychiatric morbidity, comorbidity and personality in patients with anorexia nervosa compared to their healthy sisters. Eur. Eat. Disord. Rev. 104, 255-270. doi: 10.1002/erv.476

Kaye, W. H., Lilenfeld, L. R., Berrettini, W. H., Strober, M., Devlin, B., Klump, K. L., Goldman, D., Bulik, C. M., Halmi, K. A., Fichter, M. M., Kaplan, A., Woodside, D. B., Treasure, J., Plotnicov, K. H., Pollice, C., Rao, R. and McConaha, C. W. (2000). A search for susceptibility loci for anorexia nervosa: Methods and sample description. Biological Psychiatry. 47(9), 794-803. doi: 10.1016/S00063223(99)00240-1

Kaye, W., Wierenga, C., Bailer, U., Simmons, A., Wagner, A. and Bischoff-Grethe, A., (2013). Does a shared neurobiology for foods and drugs of abuse contribute to extremes of food ingestion in anorexia and bulimia nervosa? Biol. Psychiatry 73, 836-842. doi:doi:10.1016/j.biopsych.2013.01.002 
Keller, M. B., Lavori, P. W., Friedman, B., Nielsen, E., Endicott, J., McDonald- Scott, P. \& Andreasen, N. C. (1987). The longitudinal interval follow-up evaluation: A comprehensive method for assessing outcome in prospective longitudinal studies. Archives of General Psychiatry. 44, 540-548.

Liang, K.-Y., Zeger, S.L.,(1986). Longitudinal Data Analysis Using Generalized Linear Models. Biometrika 73, 13-22.

Lovibond, S.H. and Lovibond, P.F., (1998). Manual for the depression anxiety stress scales. Psychology Foundation, Syndey.

McClintock, S.M., Husain, M.M., Greer, T.L., Cullum, C.M. (2010). Association between depression severity and neurocognitive function in major depression disorder: a review and synthesis. Neuropsychology 24(1), $9-34$.

Micali, N., Holliday, J., Karwautz, A., Haidvogl, M., Wagner, G., Fernandez-Aranda, F., Badia, A., Giminez, L., Solano, R., Brecelj-Anderluh, M., Mohan, R., Collier, D. and Treasure, J. L. (2007). Childhood eating and weight in eating disorder: A multi-centre European study of affected women and their unaffected sisters. Psychotherapy and Psychosomatics. 76, 234-241. DOI: 10.1159/000101502 Nelson, H.E. and Wilson, J.R., (1991). National Adult Reading Test (NART). Test manual (2nd ed.). Windsor, UK: NFER-Nelson.

Nigg, J.T., (2000). On inhibition/disinhibition in developmental psychopathology: views from cognitive and personality psychology and a working inhibition taxonomy. Psychol. Bull. 162, 220-246. 
Owens, M., Stevenson, J., Hadwin, J. A. and Norgate, R. (2014). When does anxiety help of hinder cognitive test performance? The role of working memory capacity. British Journal of Psychology. 105, 92-101. doi: 10.1111/bjop.12009

Peeters, H., Van Gestel, S., Vlietinck, R., Derom, C. and Derom, R., (1998). Validation of a Telephone Zygosity Questionnaire in Twins of Known Zygosity. Behav. Genet. 28, 159-163. doi:doi: 10.1023/a:1021416112215

Plomin, R., De Fries, J.C., McClearn, G.E. and McGuffin, P., (2001). Behavioral Genetics, 4th ed. Worth Publishers., New York.

Roberts, M., Tchanturia, K. and Treasure, J. (2010). Exploring the neurocognitive signature of poor set-shifting in anorexia and bulimia nervosa. J Psychiat Res, 44, 964-970.

Roberts, M., Tchanturia, K. and Treasure, J., (2013). Is attention to detail a similarly strong candidate endophenotype for anorexia nervosa and bulimia nervosa? World J. Biol. Psychiatry 14, 452-456.

Rothman, K.J., (1990). No Adjustments Are Needed for Multiple Comparisons. Epidemiology 1, $43-$ 46.

Stice, E., Telch, C. and Rizvi, S., (2000). Development and validation of the eating disorder diagnostic scale: A brief self-report measure of anorexia nervosa, bulimia, and binge eating disorder. Psychol. Assess. 12, 123-131.

Svaldi, J., Brand, M. and Tuschen-Caffier, B., (2010). Decision-making impairments in women with binge eating disorder. Appetite 54, 84-92. doi:doi: 10.1016/j.appet.2009.09.010 
Takahashi, Y., Yamagata, S., Kijima, N., Shigemasu, K., Ono, Y. and Ando, J., (2007). Continuity and change in behavioral inhibition and activation systems: A longitudinal behavioral genetic study. Personal. Individ. Differ. 43, 1616-1625. doi: 10.1016/j.paid.2007.04.030

Tchanturia, K., Harrison, A., Davies, H., Roberts, M., Oldershaw, A., Stahl, D., Morris, R., Schmidt, U. and Treasure, J. (2011) Cognitive Flexibility and Clinical Severity in Eating Disorders. PLOS ONE 6(6):e20462. doi:10.1371/journal.pone.0020462

Tenconi, E., Santonastaso, P., Degortes, D., Bosello, R., Titton, F., Mapelli, D. and Favarro, A. (2010). Set- Shifting abilities, central coherence, and handedness in anorexia nervosa patients, their unaffected siblings and healthy controls: exploring putative endophenotypes. World J Bio Psychia, 11, 813-823.

Uher, R., Brammer, M.J., Murphy, T., Campbell, I.C., Ng, V.W., Williams, S.C.R. and Treasure, J., (2003(. Recovery and chronicity in anorexia nervosa: brain activity associated with differential outcomes. Biol. Psychiatry 54, 934-942.doi: 10.1016/s0006-3223(03)00172-0

Van den Eynde, F., Guillaume, S., Broadbent, H., Stahl, D., Campbell, I.C., Schmidt, U. and Tchanturia, K., (2011). Neurocognition in bulimic eating disorders: a systematic review. Acta Psychiatr. Scand. 124, 120-140. doi: 10.1111/j.1600-0447.2011.01701.x

Wade, T.D., Tiggeman, M., Bulik, C.M., Fairburn, C.G., Wray, N.R. and Martin, N.G., (2008). Shared Temperament Risk Factors for Anorexia Nervosa: A Twin Study. Psychosom. Med. 70, 239-244. doi:doi: 10.1097/PSY.0b013e31815c40f1 
Wierenga, C. E., Ely, A., Bischoff-Grethe, A., Bailer, U. F., Simmons, A. N., \& Kaye, W. H. (2014). Are extremes of consumption in eating disorders related to an altered balance between reward and inhibition?. Frontiers in behavioral neuroscience, 8, 410

Wu, M., Brockmeyer, T., Mecthild, H., Skunde, M., Herzog, W. and Friederich, H.-C., (2016). Rewardrelated decision making in eating and weight disorders: A systematic review and meta-analysis of the evidence from neuropsychological studies. Neurosci Biobehav Rev 61, 177-96. :doi:

10.1016/j.neubiorev.2015.11.017.

This article is protected by copyright. All rights reserved. 
Table 1: Demographic and clinical features for twins with a lifetime eating disorder diagnosis and their non-eating disorder cotwins separated by zygosity

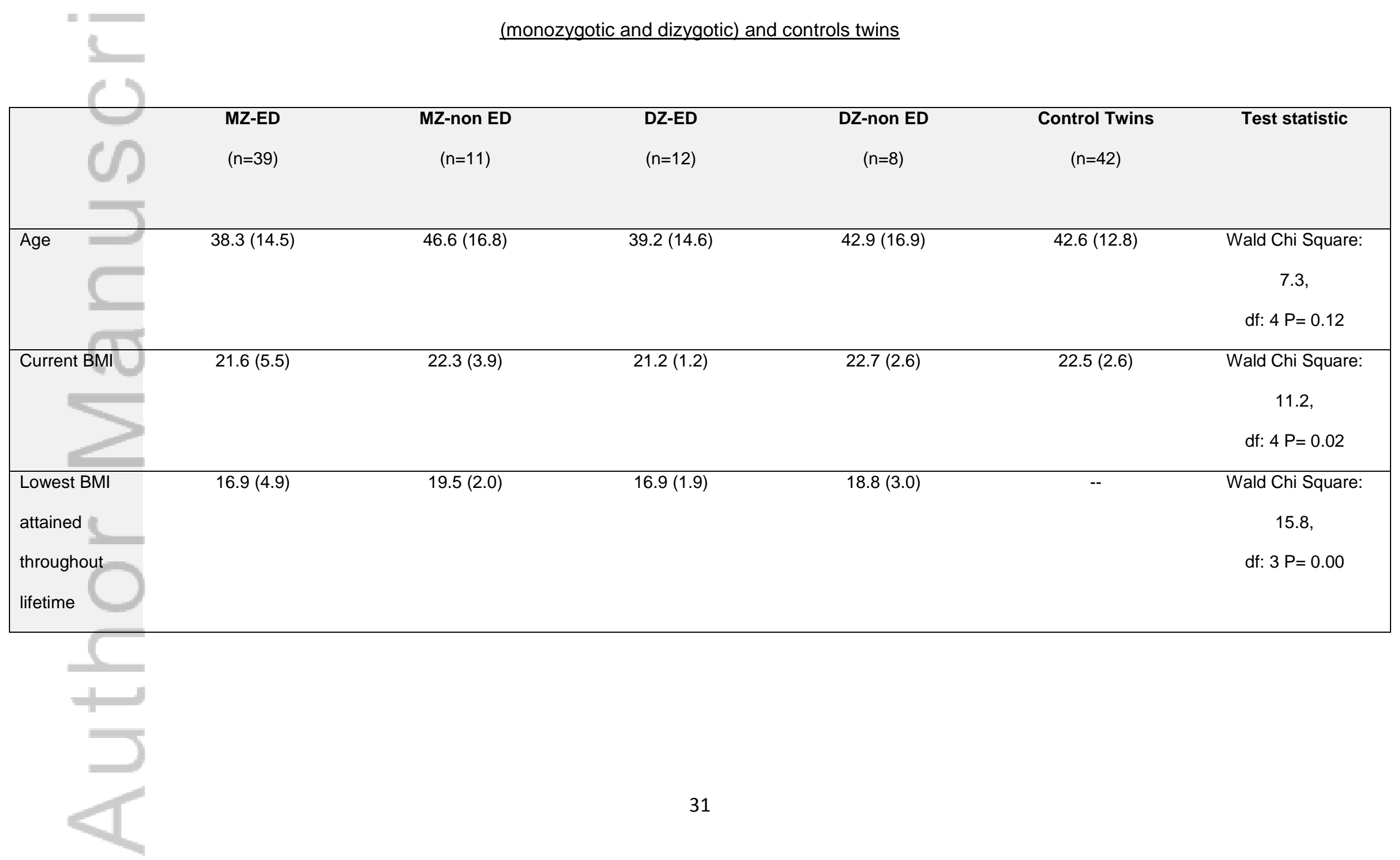

This article is protected by copyright. All rights reserved. 


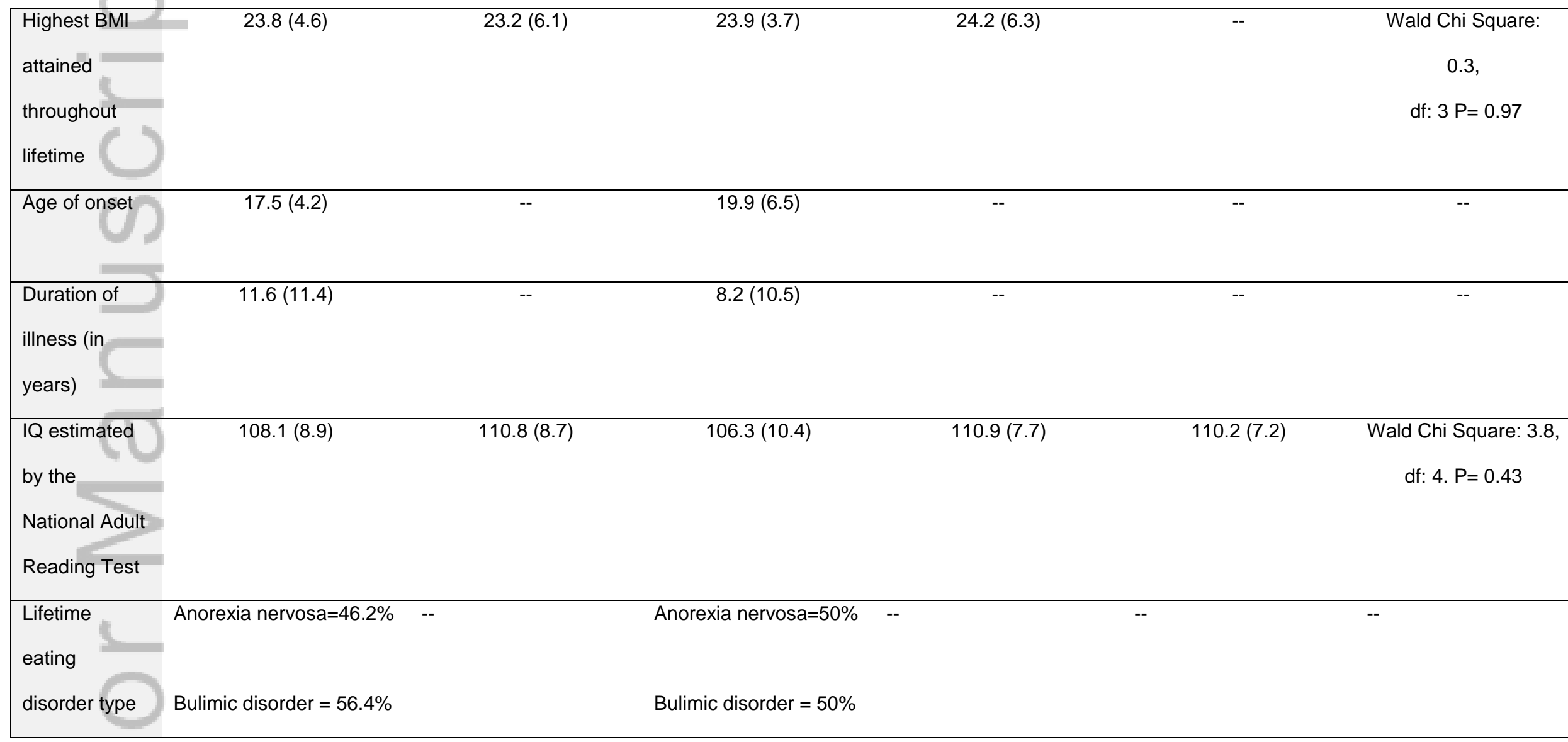




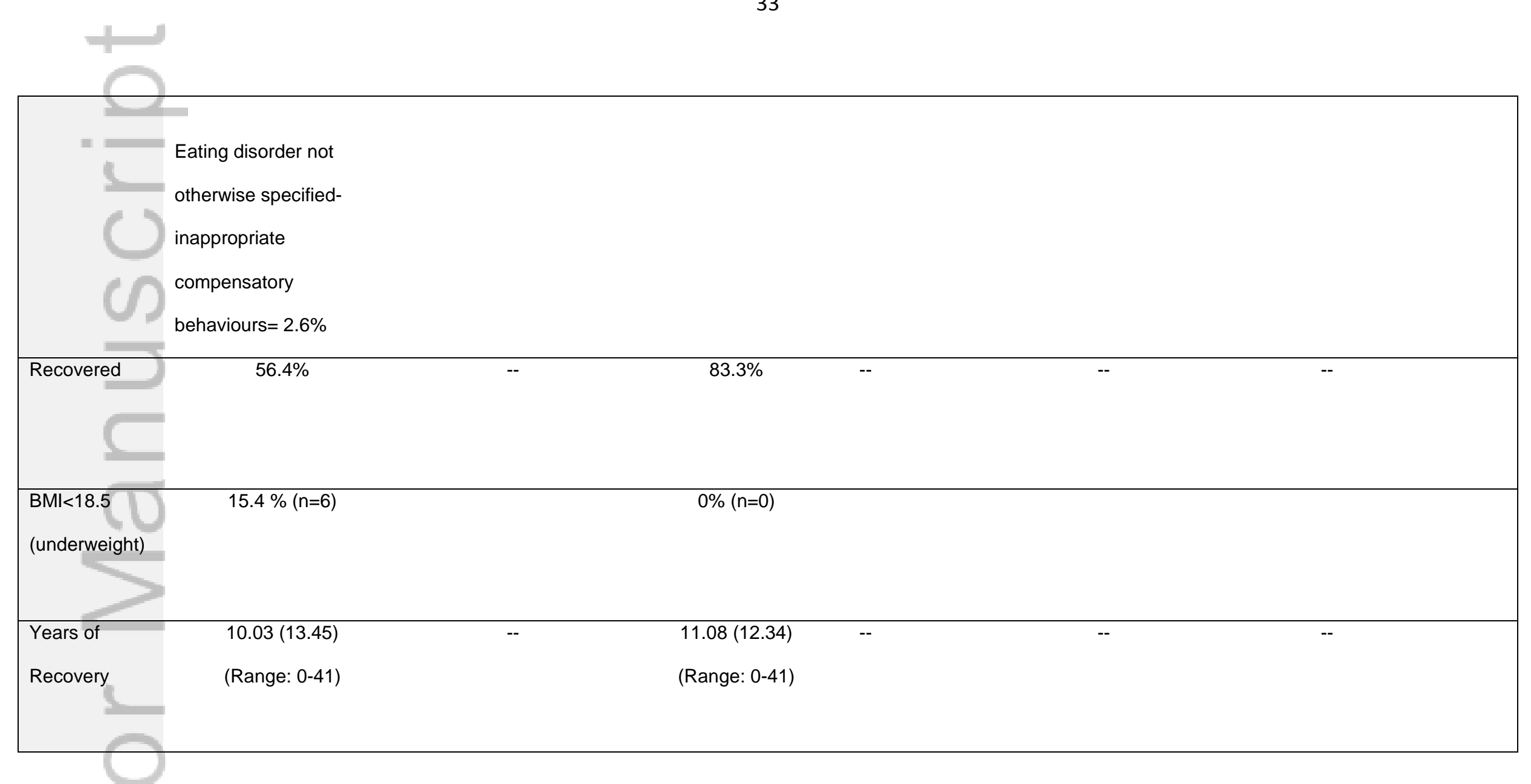

Twins are separated on the basis of zygosity and clinical status

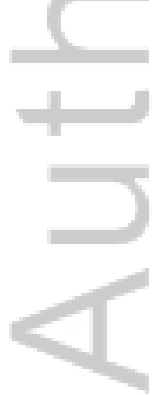

This article is protected by copyright. All rights reserved. 
MZ-ED: Monozygotic eating disorder twins

MZ-non ED: Monozygotic non-eating disorder cotwin

DZ-ED: Dizygotic eating disorder twins

DZ-non ED: Dizygotic non-eating disorder cotwin

$$
\text { and standard }
$$

Means and standard deviation in brackets (1.d.p.)
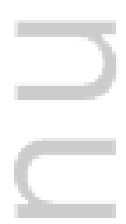

Table 2: Analysis of the reward reactivity in eating disorders and as a familial trait

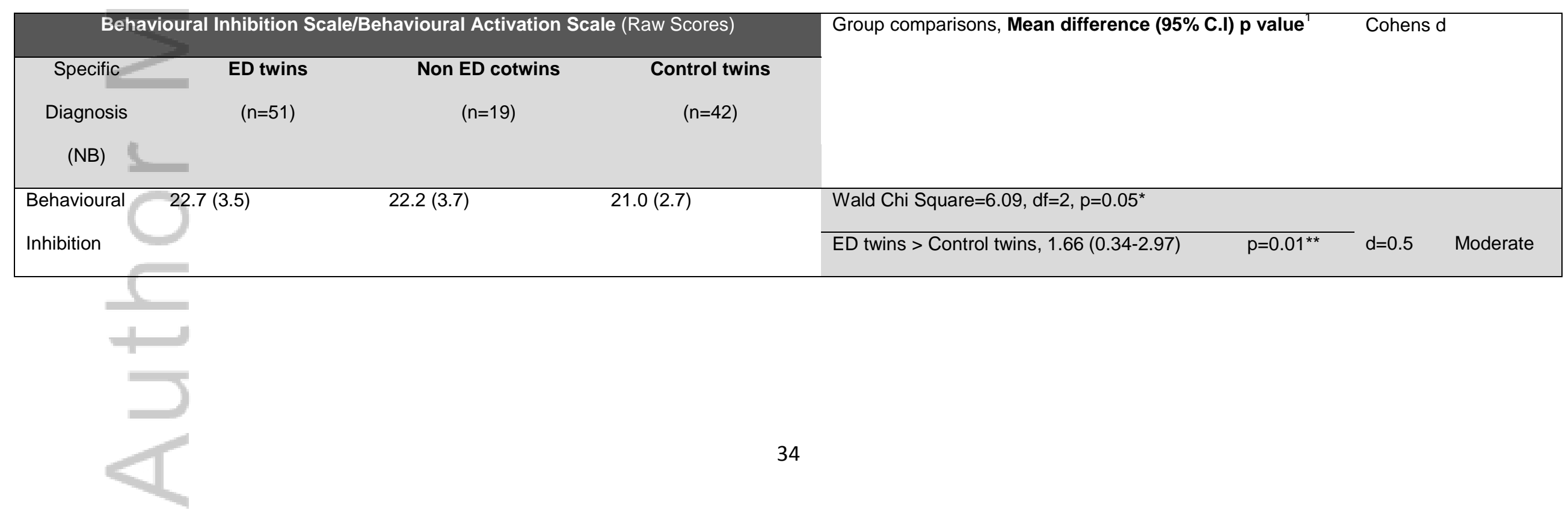

This article is protected by copyright. All rights reserved. 


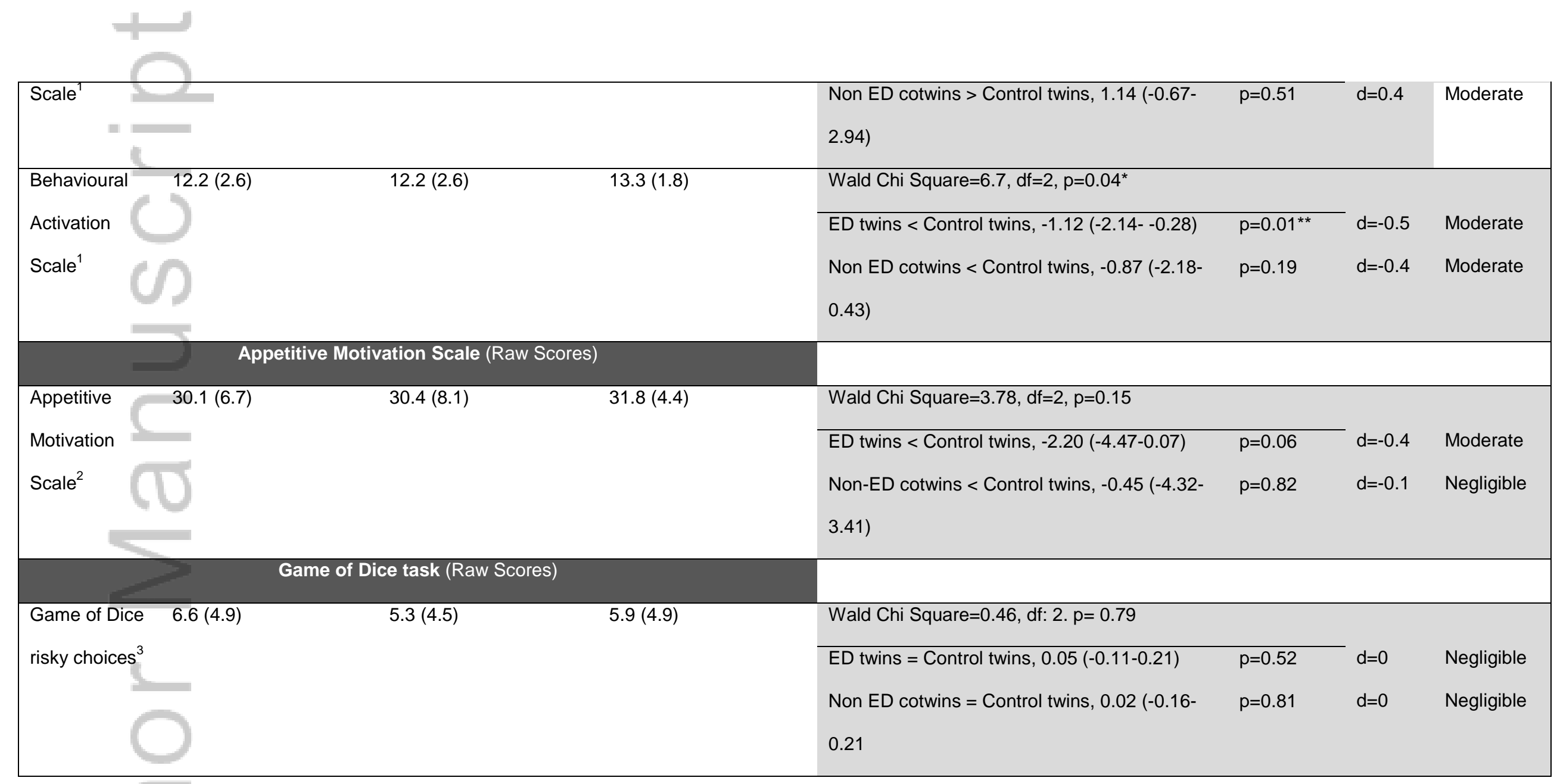


ED twins: Monozygotic twins and dizygotic twins with eating disorders

Non-ED cotwins: Monozygotic and dizygotic non-eating disorder cotwins

Controls twins: monozygotic and dizygotic twins

Descriptive statistics presented are raw means and standard deviations (1 d.p)

1 Data analysis about the Behavioural Inhibition Scale/Behavioural Activation Scale were analysed with age included as a covariate

2 Data analysis about the Appetitive Motivation Scale were analysed with age included as a covariate

3 Data analysis about the Game of Dice task (risky choices) were analysed after a logarithm transformation and age included as a covariate.

${ }^{*}=\mathrm{P}<0.05,{ }^{* *}=\mathrm{P}<0.01$

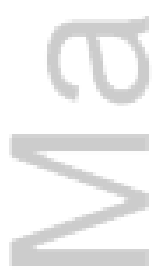

Table 3: Analysis of the reward reactivity for 'overall groups' sub-divided by eating disorder diagnosis and as a familial trait

This article is protected by copyright. All rights reserved. 
Behavioural Inhibition Scale/Behavioural Activation Scale (Raw Scores)

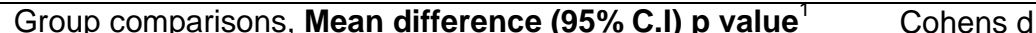

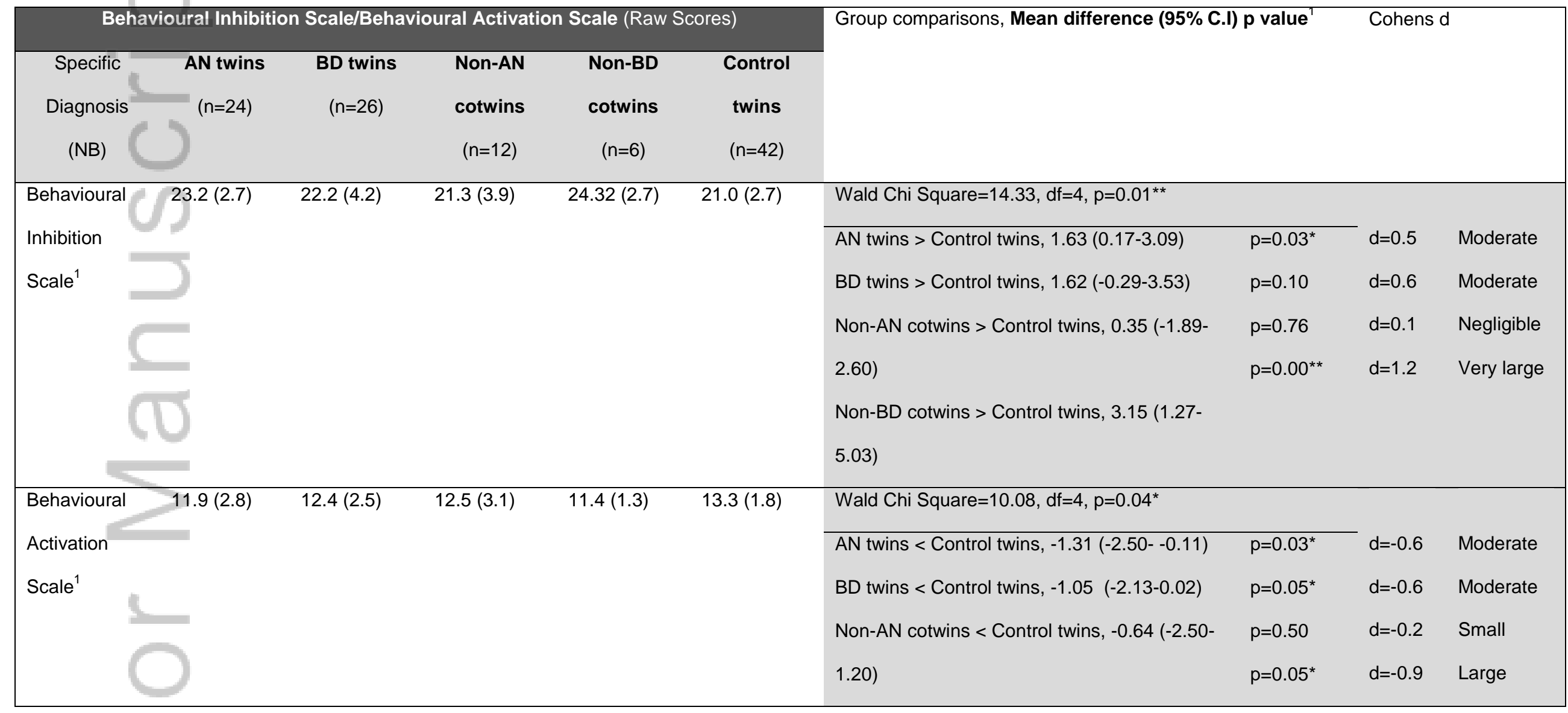

This article is protected by copyright. All rights reserved. 


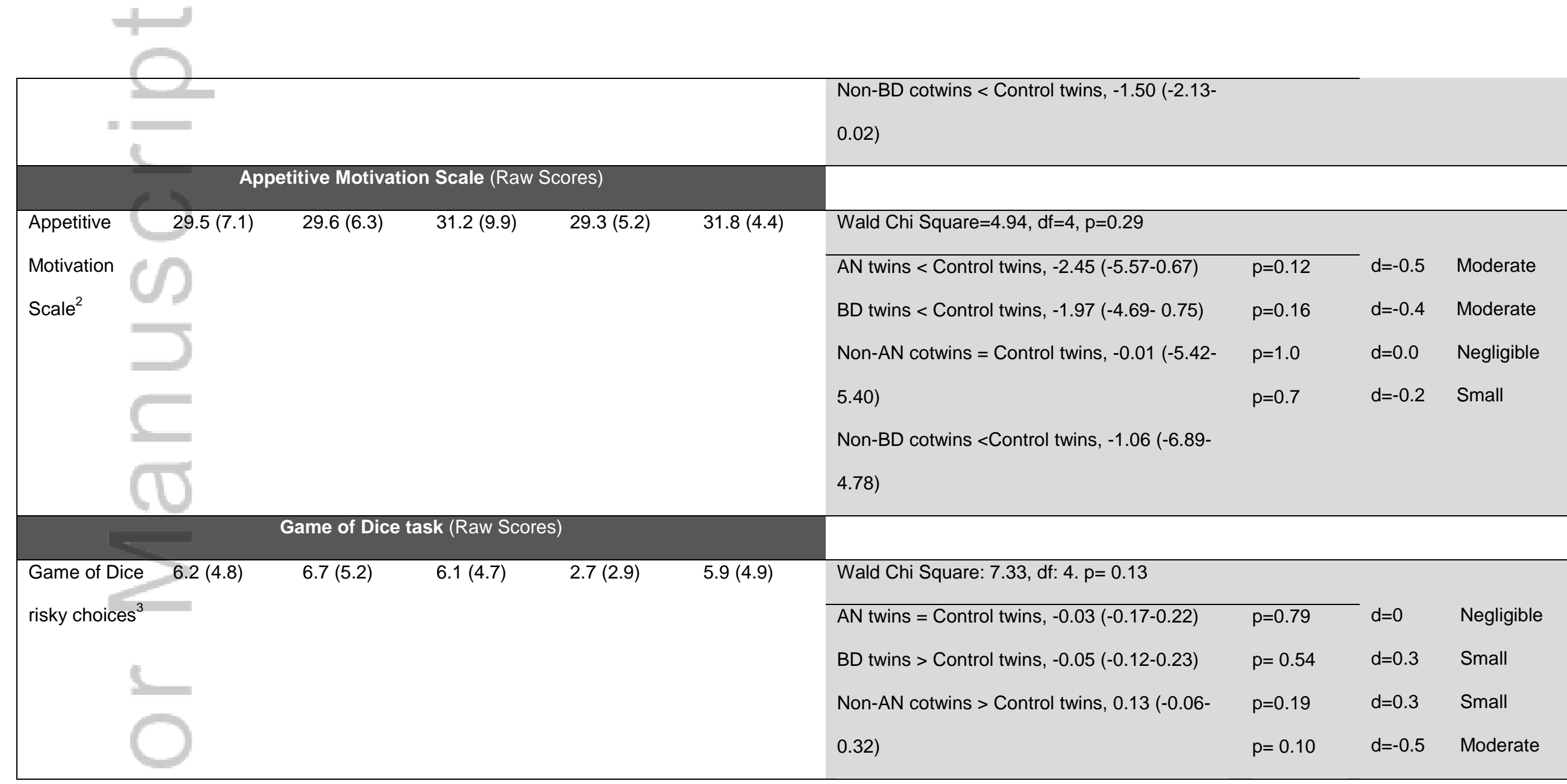




\begin{tabular}{ll|}
\hline & \\
\hline & Non-BD cotwins < Control twins, $-0.22(-0.49-$ \\
\hline
\end{tabular}

NB: monozygotic twin pair whose proband had a diagnosis of eating disorder not otherwise specified-inappropriate compensatory behaviours was excluded from this analysis.

AN twins: monozygotic and dizygotic twins with anorexia nervosa (anorexia nervosa-restrictive, anorexia nervosa-binge purge and eating disorder not otherwise specified-anorexia nervosa)

BD twins: monozygotic and dizygotic twins with bulimic disorders (bulimia nervosa, eating disorder not otherwise specified-bulimia nervosa and binge eating disorder)

Non-AN cotwins: monozygotic and dizygotic non-anorexia nervosa cotwins

Non-BD cotwins: monozygotic and dizygotic non-bulimic disorder cotwins

Controls twins: monozygotic and dizygotic control twins

(D)

Descriptive statistics presented are raw means and standard deviation in brackets (1 d.p)

1 Data analysis about the Behavioural Inhibition Scale/Behavioural Activation Scale were analysed with age included as a covariate 20.

2 Data analysis about the Appetitive Motivation Scale were analysed with age included as a covariate

3 Data analysis about the Game of Dice task (risky choices) were analysed after a logarithm transformation and age included as a covariate.

${ }^{*}=\mathrm{P}<0.05,{ }^{*}=\mathrm{P}<0.01$

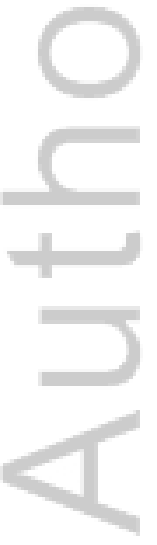

This article is protected by copyright. All rights reserved. 


\section{University Library}

\section{- M M N E R VA A gateway to Melbourne's research publications}

Minerva Access is the Institutional Repository of The University of Melbourne

Author/s:

Kanakam, N;Krug, I;Collier, D;Treasure, J

Title:

Altered Reward Reactivity as a Behavioural Endophenotype in Eating Disorders: A Pilot Investigation in Twins

Date:

2017-05-01

Citation:

Kanakam, N., Krug, I., Collier, D. \& Treasure, J. (2017). Altered Reward Reactivity as a Behavioural Endophenotype in Eating Disorders: A Pilot Investigation in Twins. EUROPEAN EATING DISORDERS REVIEW, 25 (3), pp.195-204. https://doi.org/10.1002/erv.2512.

Persistent Link:

http://hdl.handle.net/11343/292768 